\title{
KERANGKA DASAR DAN LANDASAN PENGEMBANGAN KURIKULUM 2013
}

\author{
Suarga \\ Fakultas Tarbiyah \& Keguruan \\ UIN Alauddin Makassar
}

\begin{abstract}
The history of education travel in Indonesia, the curriculum has become a negative stigma in society because of frequent change but the quality is still doubtful. The curriculum is a means to achieve the desired educational program. As a means, the curriculum will be meaningless if it is not supported by the necessary facilities and infrastructure such as adequate teaching and learning resources, the ability of the teaching staff, appropriate methodology, and clarity of direction and objectives to be achieved. Fundamentals of the 2013 curriculum, according to Mulyoto is a matter of learning approach. During this time, the approach used is the material. So the material given to the students as much as possible so that they master the material to the fullest. Even for the sake of mastery of the material, drilling has been given since the beginning, long before students face the national exam. In such learning, learning objectives of learning objectives are achieved more to the kognitif aspect by negating the psychometric and affective aspects.
\end{abstract}

Keywords: Education, Basis of Curriculum

\section{Pendahuluan}

$\mathrm{P}$ engembangan kurikulum sebenarnya merupakan salah satu upaya untuk meningkatkan kualitas pendidikan. Ia sebagai instrumen yang membantu praktisi pendidikan untuk memenuhi kebutuhan peserta didik dan kebutuhan masyarakat. Caswell menyatakan bahwa pengembangan kurikulum merupakan alat untuk membantu guru melakukan tugasnya mengajar dan memenuhi kebutuhan masyarakat. Pengembangan kurikulum tidak pernah berhenti, ia merupakan proses yang berkelanjutan dan proses siklus yang terus menerus sejalan dengan perkembangan dan tuntutan perubahan masyarakat. Pada kenyataannya, sejak awal siswa-siswa telah dibiasakan menghadapi soal-soal model ujian nasional. Pembelajaran mengacu pada kompetensi dasar yang yang nanti akan diujikan dalam ujian nasional. Bahkan ada pula guru yang menggunakan soal-soal ujian nasional yang telah diujikan pada tahun sebelumnya sebagai acuan dalam pembelajaran. Menjelang menghadapi ujian nasional, guru memberikan pembelajaran ujian nasional pada siswanya. Apapun yang tidak ada kaitannya dengan ujian nasional ditiadakan.

Berdasarkaan pengalaman selama ini, hal tersebut harus didukung dengan kebijakan yang konsisten, yaitu sistem avaluasi yang mengukur pencapaian kemampuan kognitif, psikomotorik dan afektif secara berimbang. Tidak bisa dipungkiri bahwa ujian 
nasional harus dihapuskan, sehingga penentu kelulusan nantinya adalah transkrip nilai yang diperoleh dari nilai rapor tiap semester. Karena nilai-nilai rapor sebagai hasil evaluasi pembelajaran mengandung ketiga aspek secara menyeluruh, maka pembelajaran juga akan diberikan seccara benyeluruh dalam ketiga aspek itu.

Dengan dihapusnya ujian nasional, wewenang mengadakan evaluasi kembali kepada guru sehingga lengkaplah kewenangan guru; menyusun rencana pembelajaran, melaksanakn kegiatan pembelajaran dan melaksanakan kegiatan evaluasi. Hal ini sesuai dengan UU No. 20 Tahun 2003 tentang Sistem Pendidikan Nasional. ${ }^{1}$

\section{PEMBAHASAN}

\section{A. Kerangka Dasar Kurikulum 2013}

Hal mendasar dari kurikulum 2013, menurut Mulyoto adalah masalah pendekatan pembelajarannya. Selama ini, pendekatan yang digunakan adalah materi. Jadi materi di berikan pada anak didik sebanyak-banyaknya sehingga mereka menguasai materi itu secara maksimal. Bahkan demi penguasaan materi itu, drilling sudah diberikan sejak awal, jauh sebelum siswa menghadapi ujian nasional. Dalam pembelajaran seperti ini, tujuan pembelajaran tujuan pembelajaran yang dicapai lebih kepada aspek kgnitif dengan menafikan aspek psikomotrik dan afektif.

Ketiga aspek tersebut sebenarnya sudah mendapat penekanan pada kurikulum kita selama ini. Pada saat pemberlakuan Kurikulum Berbasis Kompetensi (KBK) 2003, aspek kognitif, psikomotorik dan afektif (yang dikenal dengan taksonomi Bloom tentang tujuan pendidikan), telah juga menjadi kompetensi integral yang harus dicapai. Lalu pada saat pemberlakuan Kurikulum 2006, melalui pendidikan karakter, aspek afektif yang seolah dilupakan para praktisi pendidikan, digaungkan. Tapi dalam dataran praksis, hanya aspek kognitif yang dikejar. Penyebabnya adalah kurikulum tidak dikawal dengan kebijakan yang sinergis, tetapi malah dijegal dengan kebijakan ujian nasional.

Soal-soal ujian nasional hanya menguji pencapaian aspek kognitif. Pencapaian aspek psikomotorik dan afektif tidak bisa diukur dengan menggunakan tes ini. Padahal tes ini adalah penentu kelulusan. Maka pembelajaran yang terjadi adalah pembelajaran yang berbasis materi tanpa memedulikan penanaman keterampilan dan sikap. Pada kenyataannya, sejak awal siswa-siswa telah dibiasakan menghadapi soal-soal model ujian nasional. Pembelajaran mengacu pada kompetensi dasar yang yang nanti akan diujikan dalam ujian nasional. Bahkan ada pula guru yang menggunakan soal-soal ujian nasional yang telah diujikan pada tahun sebelumnya sebagai acuan dalam pembelajaran. Menjelang menghadapi ujian nasional, guru memberikan pembelajaran ujian nasional pada siswanya. Apapun yang tidak ada kaitannya dengan ujian nasional ditiadakan.

\footnotetext{
114-115.

${ }^{1}$ Mulyoto, Strategi Pembelajaran di Era Kurikulm 2013 (Jakarta: Prestasi Pustaka Raya, 2013) h.
} 
Berdasarkaan pengalaman selama ini, hal tersebut harus didukung dengan kebijakan yang konsisten, yaitu sistem avaluasi yang mengukur pencapaian kemampuan kognitif, psikomotorik dan afektif secara berimbang. Tidak bisa dipungkiri bahwa ujian nasional harus dihapuskan, sehingga penentu kelulusan nantinya adalah transkrip nilai yang diperoleh dari nilai rapor tiap semester. Karena nilai-nilai rapor sebagai hasil evaluasi pembelajaran mengandung ketiga aspek secara menyeluruh, maka pembelajaran juga akan diberikan seccara benyeluruh dalam ketiga aspek itu. Dengan dihapusnya ujian nasional, wewenang mengadakan evaluasi kembali kepada guru sehingga lengkaplah kewenangan guru; menyusun rencana pembelajaran, melaksanakn kegiatan pembelajaran dan melaksanakan kegiatan evaluasi. Hal ini sesuai dengan UU No. 20 Tahun 2003 tentang Sistem Pendidikan Nasional. ${ }^{2}$

\section{B. Landasan Kurikulum 2013}

Dalam setiap pengemangan kurikulum pasti ada landasan-landasan yang digunakan. Berikut ini landasan-landasan yang digunakan dalam pengembangan kurikulum 2013.

1. Landasan Filosofis

a. Filosofis pancasila yang memberikan berbagai prinsip dasar dalam pembangunan pendidikan.

b. Filosofis pendidikan yang berbasis pada nilai-nilai luhur, nilai akademik, kebutuhan peserta didik, dan masyarakat.

Dari sumber lain menjelaskan mengenai landasan filosofis kurikulum 2013 sebagai berikut:

1) Pendidikan berakar pada budaya bangsa, kehidupan masa kini dan membangun landasan kehidupan masa depan.

2) Pendidikan adalah proses pewarisan dan pengembangan budaya.

3) Pendidikan memberikan dasar bagi untuk peserta didik berpartisipasi dalam membangun kehidupan masa kini.

4) Pendidikan mengembangkan berbagai potensi yang dimiliki peserta didik

5) Pendidikan adalah proses pengembangan jatidiri peserta didik.

6) Pendidikan menempatkan peserta didik sebagai subjek yang belajar. ${ }^{3}$

2. Landasan Yuridis

Secara yuridis, kurikulum adalah suatu kebijakan publik yang didasarkan kepada dasar filosofis bangsa dan keputusan yuridis di bidang pendidikan. Landasan yuridis kurikulum adalah Pancasila dan Undang-undang Dasar 1945, Undang-undang nomor 20 tahun 2003 tentang Sistem Pendidikan Nasional, Peraturan Pemerintah nomor 19 tahun

\footnotetext{
${ }^{2}$ Mulyoto, Strategi Pembelajaran di Era Kurikulm 2013, h. 115.

${ }^{3}$ S. Hamid Hasan, Workshop/ kurikulum 2013 di SMP 19/materi pelatihan IPS kur 2013/penyegaran narsum 2013/milenium 26-28 Juni 2013.
} 
2005, dan Peraturan Menteri Pendidikan Nasional nomor 23 tahun 2006 tentang Standar Kompetensi Lulusan dan Peraturan Menteri Pendidikan Nasional nomor 22 tahun 2006 tentang Standart isi.

1. RPJMM 2010-2014 Sektor Pendidikan, tentang perubahan Metodologi Pembelajaran dan Penataan Kurikulum.

2. PP. No.19 tahun 2005 tentang Standart Nasional pendidikan.

3. INPRES No. 1 tahun 2010, tentang percepatan pelaksanaan Prioritas pembangunan Nasional, penyempurnaan kurikulum dan metode pembelajaran aktif berdasarkan nilai-nilai budaya bangsa untuk membentuk daya asing dan karakter bangsa.

Beberapa landasan yuridis dari Undang-Undang sebagai berikut:

a. UUD Negara Republik Indonesia Tahun 1945

b. UU nomor 20 Tahun 2003 tentang sistem pendidikan nasional

c. UU no. 17 tahun 2005 tentang rencana pembangunan jangka panjang nasional, beserta segala ketentuan yang dituangkan rencana pembangunan jangka menengah nasional, dan

d. Peraturan pemerintah no. 19 tahun 2005 tentang standart nasional pendidikan sebagaimana telah diubah dengan PP no. 19 tahun 2005 tentang standart nasional pendidikan. ${ }^{4}$

3. Landasan Konseptual
a. Relevansi pendidikan
b. Kurikulum berbasis kompetensi dan karakter
c. Pembelajaran kontekstual
d. Pembelajaran aktif
e. Penilaian yang valid, utuh dan menyeluruh. ${ }^{5}$

\section{Landasan Teoritis}

Kurikulum dikembangkan atas dasar teori pendidikan berdasarkan standart dan teori pendidikan berbasis kompetensi. Pendidikan berdasarkan standart adalah pendidikan yang menetapkan standart nasional sebagai kualitas minimal hasil belajar yang berlaku untuk setiap kurikulum. Standart kualitas nasional dinyatakan sebagai Standart Kompetensi Lulusan. Standart Kompetensi Lulusan tersebut adalah kualitas minimal lulusan suatu jenjang atau satuan pendidikan. SKL mencangkup sikap, pengetahuan, dan keterampilan (PP nimor 19 tahun 2005).

\section{Landasan Empiris}

Berbagai perubahan telah terjadi id Indonesia. Kemajuan terjadi di beberapa sektor di Indonesia, namun di beberapa sektor yang lain, khususnya pendidikan,

${ }^{4}$ Salinan lampiran Permendikbud no. 67 tahun 2013 tentang kurikulum SD, hlm. 6.

${ }^{5}$ E. Mulyasa, Pengembangan dan Implementasi Kurikulum 2013 (Bandung: PT. Remaja Rosdakarya, 2013) h. 65. 
Indonesia tetap tinggal di tempat, atau bahkan mundur. Hal-hal seperti ini menunujukkan perlunya perubahan orientasi kurikulum dengan tidak membebani peserta didik dengan konten, namun pada aspek kemampuan esensial yang diperlukan semua warga untuk berperan serta dalam membangun negara pada masa mendatang.

Dalam satu sistem pendidikan, kurikulum itu bersifat dinamis serta harus selalu dilakukan perubahan dan pengembangan, agar dapat mengikuti perkembangan dan tantangan zaman. Namun demikian, perubahan dan pengembangan kurikulum harus dilakukan secara terarah dan tidak asal-asalan.

\section{Tujuan Pengembangan Kurikulum 2013}

Kurikulum 2013 bertujuan untuk mempersiapkan manusia Indonesia agar memiliki kemampuan hidup sebagai pribadi dan warga Negara yang beriman, produktif, kreatif, inovatif, dan afektif serta mampu berkontribusi pada kehidupan bermasyarakat, berbangsa, bernegara, dan peradaban dunia.

\section{Karakteristik Kurikulum}

Beberapa hal yang baru pada kurikulum mendatang antara lain:

1. Kurikulum berbasis sains

2. Kurikulum 2013 untuk SD, bersifat tematik integratif. Mata pelajaran IPA dan IPS sebagai materi pembahasan pada semua pelajaran (IPA dan IPS diintegrasikan kedalam semua mata pelajaran).

a. IPA akan menjadi materi pembahasan pelajaran Bahasa Indonesia dan matematika

b. IPS akan menjadi pembahasan materi pelajaran Bahasa Indonesia dan PPKN.

3. Kompetensi yang ingin dicapai adalah kompetensi yang berimbang antara sikap, keterampilan, dan pengetahuan, disamping cara pembelajarannya yang holistik dan menyenangkan.

4. Proses pembelajaran menekankan aspek kognitif, afektif, psikomotorik melalui penilaian berbasis tes dan portofolio saling melengkapi.

5. Jumlah mata pelajaran ada 7:

a. Pendidikan agama,

b. Pendidikan Pancasila dan kewarganegaraan,

c. Bahasa Indonesia,

d. Matematika,

e. Seni budaya dan prakarya,

f. Pendidikan jasmani, olahraga dan kesehatan,

g. Pramuka

6. Alokasi waktu per jam pelajaran

a. $\mathrm{SD}=35$ menit

b. $\mathrm{SMP}=40$ menit 
c. $\mathrm{SMA}=45$ menit

7. Banyak jam pelajaran per minggu

a. SD: Kelas $\mathrm{I}=30$ jam, kelas $\mathrm{II}=32$ jam, kelas $\mathrm{III}=34$ jam, kelas IV, V, VI=36 jam

b. $\mathrm{SMP}=38$ jam

c. $\mathrm{SMA}=39$ jam. $^{6}$

Kurikulum berbasis kompetensi adalah "outcomes-based curriculum" dan oleh karena itu pengembangan kurikulum diarahkan pada pencapaian kompetensi yang dirumuskan dari SKL. Demikian pula penilaian hasil belajar dan hasil kurikulum diukur dari pencapaian kompetensi. Keberhasilan kurikulum diartikan sebagai pencapaian kompetensi yang dirancang dalam dokumen kurikulum oleh seluruh peserta didik. Karakteristik kurikulum berbasis kompetensi pada kurikulum tahun 2013 adalah:

1) Isi atau konten kurikulum adalah kompetensi yang dinyatakan dalam bentuk Kompetensi Inti (KI) mata pelajaran dan dirinci lebih lanjut ke dalam Kompetensi Dasar (KD).

2) Kompetensi Inti (KI) merupakan gambaran secara kategorial mengenai kompetensi yang harus dipelajari peserta didik untuk suatu jenjang sekolah, kelas, dan mata pelajaran.

3) Kompetensi Dasar (KD) merupakan kompetensi yang dipelajari peserta didik untuk suatu mata pelajaran di kelas tertentu.

4) Penekanan kompetensi ranah sikap, keterampilan kognitif, keterampilan psikomotorik, dan pengetahuan untuk suatu satuan pendidikan dan mata pelajaran ditandai oleh banyaknya KD suatu mata pelajaran. Untuk SD pengembangan sikap menjadi kepedulian utama kurikulum.

5) Kompetensi Inti menjadi unsur organisatoris kompetensi bukan konsep, generalisasi, topik atau sesuatu yang berasal dari pendekatan "disciplinary-based curriculum" atau "content-based curriculum".

6) Kompetensi Dasar yang dikembangkan didasarkan pada prinsip akumulatif, saling memperkuat dan memperkaya antar mata pelajaran.

7) Proses pembelajaran didasarkan pada upaya menguasai kompetensi pada tingkat yang memuaskan dengan memperhatikan karakteristik konten kompetensi dimana pengetahuan adalah konten yang bersifat tuntas (mastery). Keterampilan kognitif dan psikomotorik adalah kemampuan penguasaan konten yang dapat dilatihkan. Sedangkan sikap adalah kemampuan penguasaan konten yang lebih sulit dikembangkan dan memerlukan proses pendidikan yang tidak langsung.

8) Penilaian hasil belajar mencakup seluruh aspek kompetensi, bersifat formatif dan hasilnya segera diikuti dengan pembelajaran remedial untuk memastikan

${ }^{6}$ tunas63.wordpress.com/2012/11/16-karakteristik-kurikulum-baru-2013/ (Diakses 14 mei 2016). 
penguasaan kompetensi pada tingkat memuaskan (Kriteria Ketuntasan Minimal/KKM dapat dijadikan tingkat memuaskan). ${ }^{7}$

\section{PENUTUP}

Dalam setiap pengemangan kurikulum pasti ada landasan-landasan yang digunakan. Berikut ini landasan-landasan yang digunakan dalam pengembangan kurikulum 2013.

1. Landasan Filosofis

a. Filosofis pancasila yang memberikan berbagai prinsip dasar dalam pembangunan pendidikan.

b. Filosofis pendidikan yang berbasis pada nilai-nilai luhur, nilai akademik, kebutuhan peserta didik, dan masyarakat.

Dari sumber lain menjelaskan mengenai landasan filosofis kurikulum 2013 sebagai berikut:

1) Pendidikan berakar pada budaya bangsa, kehidupan masa kini dan membangun landasan kehidupan masa depan.

2) Pendidikan adalah proses pewarisan dan pengembangan budaya.

3) Pendidikan memberikan dasar bagi untuk peserta didik berpartisipasi dalam membangun kehidupan masa kini.

4) Pendidikan mengembangkan berbagai potensi yang dimiliki peserta didik

5) Pendidikan adalah proses pengembangan jatidiri peserta didik.

6) Pendidikan menempatkan peserta didik sebagai subjek yang belajar.

2. Landasan Yuridis

Secara yuridis, kurikulum adalah suatu kebijakan publik yang didasarkan kepada dasar filosofis bangsa dan keputusan yuridis di bidang pendidikan.

Landasan yuridis kurikulum adalah Pancasila dan Undang-undang Dasar 1945, Undang-undang nomor 20 tahun 2003 tentang Sistem Pendidikan Nasional, Peraturan Pemerintah nomor 19 tahun 2005, dan Peraturan Menteri Pendidikan Nasional nomor 23 tahun 2006 tentang Standar Kompetensi Lulusan dan Peraturan Menteri Pendidikan Nasional nomor 22 tahun 2006 tentang Standart isi.

1. RPJMM 2010-2014 Sektor Pendidikan, tentang perubahan Metodologi Pembelajaran dan Penataan Kurikulum.

2. PP. No.19 tahun 2005 tentang Standart Nasional pendidikan.

3. INPRES No. 1 tahun 2010, tentang percepatan pelaksanaan Prioritas pembangunan Nasional, penyempurnaan kurikulum dan metode pembelajaran aktif berdasarkan nilai-nilai budaya bangsa untuk membentuk daya asing dan karakter bangsa.

\footnotetext{
${ }^{7}$ Abdima.blogspot.com./2013/02/karakteristik-kurikulum-berbasis.html. (diakses 14 Mei 2016).
} 
Beberapa landasan yuridis dari Undang-Undang sebagai berikut:

a. UUD Negara Republik Indonesia Tahun 1945

b. UU nomor 20 Tahun 2003 tentang sistem pendidikan nasional

c. UU no. 17 tahun 2005 tentang rencana pembangunan jangka panjang nasional, beserta segala ketentuan yang dituangkan rencana pembangunan jangka menengah nasional, dan

d. Peraturan pemerintah no. 19 tahun 2005 tentang standart nasional pendidikan sebagaimana telah diubah dengan PP no. 19 tahun 2005 tentang standart nasional pendidikan.

3. Landasan Konseptual
a. Relevansi pendidikan
b. Kurikulum berbasis kompetensi dan karakter
c. Pembelajaran kontekstual
d. Pembelajaran aktif
e. Penilaian yang valid, utuh dan menyeluruh.

4. Landasan Teoritis

Kurikulum dikembangkan atas dasar teori pendidikan berdasarkan standart dan teori pendidikan berbasis kompetensi. Pendidikan berdasarkan standart adalah pendidikan yang menetapkan standart nasional sebagai kualitas minimal hasil belajar yang berlaku untuk setiap kurikulum. Standart kualitas nasional dinyatakan sebagai Standart Kompetensi Lulusan. Standart Kompetensi Lulusan tersebut adalah kualitas minimal lulusan suatu jenjang atau satuan pendidikan. SKL mencangkup sikap, pengetahuan, dan keterampilan (PP nimor 19 tahun 2005).

5. Landasan Empiris

Berbagai perubahan telah terjadi id Indonesia. Kemajuan terjadi di beberapa sektor di Indonesia, namun di beberapa sektor yang lain, khususnya pendidikan, Indonesia tetap tinggal di tempat, atau bahkan mundur. Hal-hal seperti ini menunujukkan perlunya perubahan orientasi kurikulum dengan tidak membebani peserta didik dengan konten, namun pada aspek kemampuan esensial yang diperlukan semua warga untuk berperan serta dalam membangun negara pada masa mendatang.

\section{DAFTAR PUSTAKA}

Mulyoto, Strategi Pembelajaran di Era Kurikulm 2013, Jakarta: Prestasi Pustaka Raya, 2013.

Salinan lampiran Permendikbud no. 67 tahun 2013 tentang kurikulum SD, h. 6.

S. Hamid Hasan, Workshop/ kurikulum 2013 di SMP 19/materi pelatihan IPS kur 2013/penyegaran narsum 2013/milenium 26-28 Juni 2013. 
tunas63.wordpress.com/2012/11/16-karakteristik-kurikulum-baru-2013 / (Diakses 14 mei 2016).

Abdima.blogspot.com./2013/02/karakteristik-kurikulum-berbasis.html. (Diakses 14 Mei 2016). 